Methods We performed a literature review regarding the fitness to drive among CMV drivers with OSAS.

Result CMV drivers are a high risk, underserved occupational group. Occupational demands and working conditions result in a sedentary lifestyle and irregular sleeping patterns, contributing to overweight and fatigue. Occupational risks and morbidities include e.g. hypertension, metabolic syndrome and diabetes. Subjective EDS can be assessed by questionnaires (e. g. STOP-Bang, Berlin Questionnaire, Epworth Sleepiness Scale), unfortunately with reporting bias. Measurement of height and weight (body mass index), neck circumference and blood pressure during physical examination offers an opportunity to assess objective risk factors for OSAS without relying on the subjective report.

Discussion OSAS is both underdiagnosed and undertreated. Identifying CMV drivers, with OSAS and treating them effectivily should decrease crash-related fatalities and injuries. There is a need for an active response from (occupational health) physicians, the sleep disorder specialists, the transport industry and the governments to create an effective OSAS screening among drivers and to accomplish patient compliance with the best treatment.

An objective evaluation is expensive, time consuming and not applicable on a large scale. New tools are necessary to assess the fitness to drive. There is a lack of such tools, as well as practical guidelines, so there is no consensus on the driving ability of untreated and treated OSAS patients.

\section{CHALLENGES FOR THE BETTER SCREENING OF SLEEP APNEA SYNDROME IN A RAILWAY COMPANY IN JAPAN}

\footnotetext{
${ }^{1,2}$ Shuhei Morizane*, ${ }^{2}$ Yoshiyuki Kanagawa, ${ }^{2}$ Kaoru Mizoguchi, ${ }^{2}$ Etsuo Kasahara, ${ }^{2}$ Yasutoshi Yuguchi, ${ }^{1}$ Jinro Inoue, 'Seichi Horie. 'Department of Health Policy and Management, Institute of Industrial Ecological Sciences, University of Occupational and Environmental Health (UOEH), Kitakyushu, Japan; ${ }^{2} J R$ East Health Promotion Centre, Tokyo, Japan
}

\subsection{6/oemed-2018-ICOHabstracts.59}

Introduction SAS is known to cause drowsiness and lack of concentration at work and poses a serious job-fitness risk as a train driver. E company launched the initial screening program in 2003 using Epworth Sleepiness Scale (ESS) and induced pulse oximetry in 2007, and examin all train drivers every three years.

Methods Ased on ESS and pulse oximetry the detailed examination using sleeping polysomnography (PSG). Crews who need medical treatment such as continuous positive airway pressure (CPAP) were subject to work restrictions until the improvement was confirmed.

Results According to the statistics for 9 years until October 2016, 5500 crews examined 151 crews were subject to work restrictions.

After treatment, more than $90 \%$ of the cases have recovered their AHI to less than 30\% of previous level, and all drivers successfully returned to their original jobs in about 2 weeks.

Discussions Arger proportion of SAS patients (2.7\%) than average Japanese population (1.7\%, Guidelines for Diagnosis and Treatment of Sleep Disordered Breathing in Cardiovascular Disease), company is still experiencing false negative cases improve the drivenvironment to prevent daytime drowsiness and educations for crew members.
1082

FACTORS ASSOCIATED WITH SHARP DEVICE INJURIES IN DAMMAM HEALTHCARE WORKERS: IMPLICATIONS FOR PREVENTION

Sultan Al-Otaibi, Kifah Alfulayw, Philip Harber, Hassan Abugad. Imam Abdulrahman Bin Faisal University, Damam, Saudi Arabia

10.1136/oemed-2018-ICOHabstracts.60

Background Sharp devices injuries (SDI) expose workers to blood-borne pathogens. Despite implementation of preventive measures to reduce sharp injuries they continue to occur in every step of sharp devices usage, disassembly or disposal.

Aims To examine risk factors of SDI and explore implications for prevention.

Methods Retrospective study of SDI incidence among healthcare workers $(\mathrm{HCW})$ at a hospital.

Results $8.4 \%$ of HCW reported an SDI over 26 months. Most occurred in wards (32\%). Nurses were most affected category by SDI $(52.5 \%)$, followed by physicians (24.9\%). Disposable syringes are the main cause among nurses (58.9\%), while surgical devices are the main cause among physicians (40\%). Expatriates with SDI are less likely than Saudis to have had a complete hepatitis B vaccination series.

Conclusion SDI are common. Because characteristics of SDI differed according to job category and worksite, preventive strategies should be targeted for each category. Adequate hepatitis $B$ vaccination is needed.

\section{OCCUPATIONAL HEALTH AND SAFETY PHILOSOPHY VISÍON ZERO AND WELLNESS PROGRAMS AT GRUPO PROGRESO}

1,2,3 Ovidio Roberto Hermosilla Colmenares. 'ISSA, Mining Section, Geneva, Switzerland ${ }^{2} \mathrm{COH}$, Industrial Hygiene, Milan, Italy; ${ }^{3}$ ASOMET, Guatemalan Occupational Heath Association, Guatemala, Guatemala

\subsection{6/oemed-2018-ICOHabstracts.61}

Objectives Demonstrate how and why the wellness of each of our employees, is the reason to focus in $\mathrm{OH}$ and $\mathrm{S}$ at Grupo Progreso, in order to achieve our 'Zero Incidents' Vision.

Methods Our strategy regarding $\mathrm{OH}$ and $\mathrm{S}$ takes us first to achieve and meet the commitment with the board of directors, top management, bosses, supervisors and every operational staff. This means we lead with the example, allowing us to show genuine interest in the health and safety of every employee. The last stage is the application of the consequences scheme, where we encourage employees to repeat desired behaviours and sanctions those who break safety regulations. We count with a lead indicator, called Safety Gradient, that was designed by our team and it is monitored since the last 4 years every week in every team during group meeting all around the organisation. The top management, the CEO and the $\mathrm{OH}$ and $\mathrm{S}$ corporate manager also go through this tool each week. This indicator takes into account four elements: Safety moments, Safety observations, Corrective actions and Stopped unsafe acts. In addition, each week the $\mathrm{OH}$ and $\mathrm{S}$ team will perform inspections in different areas that provide the percentage of safe behaviour and safety conditions. Because this is a predictive tool, the incidents that involve injuries that need medical treatment without lost time and property damage will change the percentage of the Safety Gradient. This value allows us to know the safety level under which our organisation is run. 
Genuine leadership is essential to transform a reactive culture into a preventive one.

Annually different capacitation plans are generated for all employees and corresponding competences are developed so they can perform their job in a safety way.Communication and awareness must continually be directed towards employees when sharing relevant discussions of incidents that have occurred to make sure they don't happen again. The methodology of risks assessment is done in a structured process, where every activity must have a risk analysis before starting it. Every day, every shift work and every critical task. We are respectful towards the fulfilment of every legal requirement that apply to us.

Results We went from a frequency index of 14.8 in 2000 to a LTIFR of 2.4 on 2003, where we had an increase is due to the consideration of incidents with contractors, visitors and third parties. Since 2006 we have had a constant decrease that has taken us to a LTIFR of 0.19 and a LTISR of 16 up to 2016 (ANSI 16.1).

Progreso has been awarded with several titles including: First guatemalan company acknowledged as one of the top ethical organisations by Ethisphere Institute. Since 2009 until 2017, we were awarded by the Great Place to Work Institute. At 2016 an 2017 the British Safety Council awarded us with recognition for our practices and good results in Occupational Health and Safety.

So we have achieved operations with ZERO injuries in different companies at Grupo Progreso.

Conclusion Ellness of our employees as objective and a strategy of commitment and genuine leadership, communication, competences, acknowledgement of safe acts, rigorous monitoring of predicting indicators and a minimum tolerance towards jobs under risk it is possible to achieve operations with zero incidents.

\section{A TRAINING VIDEO EXPERIENCE FOR HANDLING IN AIRCRAFT HOLD WITH AN EXTENDABLE ROLLER TRACK CONVEYOR}

${ }^{1}$ Christian Mostosi* ${ }^{2}$ Jean-Francois Stéphenne, ${ }^{3}$ Philippe Romain, ${ }^{4}$ Frédéric Dierick. 'Attentia, Charleroi, Belgium; '2Brussels South Charleroi Airport, Charleroi, Belgium; ${ }^{3}$ Wallonie Aerotraining Network, Charleroi, Belgium; ${ }^{4}$ Haute Ecole Louvain en Hainaut, Charleroi, Belgium

\subsection{6/oemed-2018-ICOHabstracts.62}

Introduction The influence of experience, training, and use of mechanical equipment during baggage handling in a kneeling posture in the aircraft hold remain still largely unknown. However, the introduction of an extendable roller track conveyor (ERC) at the Charleroi airport allow to reduce the number of work accidents occurring in the hold. The purpose of this study was to produce a training video for baggage handlers to speed up their experience with an ERC.

Method Expert $(n=24)$ and novice $(n=34)$ handlers were filmed during real handling conditions in the hold of aircrafts to identify specific postures and movements associated to experience level. Based on these findings and ergonomic criteria, a training video of the best handling strategies associated with the use of ERC was realised. The video was showed during training sessions of 72 professional and 61 trainee baggage handlers. Results were collected by self-administered questionnaires.
Results Eighteen percent of professionals had never follow any training in handling and 35\% who have already follow a training believe that this was not relevant to the work in the hold. Seventy percent of professionals did not consider they had any good handling strategies. After seeing the video, 93\% of professionals (98\% of trainees) judge that the video is useful and $92 \%$ of professionals (97\% of trainees) that it would help them to be more careful when handling baggage. Finally, $81 \%$ of professionals believe that this project was useful and should be repeated (94\%), and 56\% report that they had changed their way of handling.

Discussion Training in handling is crucial when handling is realised in a kneeling posture in an aircraft hold using an ERC. Our results suggest that a video could be a useful tool to speed up handling experience in this specific work environment.

\section{ACCIDENT PREVENTION - ROLE OF SAFETY OBSERVATION AT WORKPLACE IN REDUCING ACCIDENTS}

Prashant Bharadwaj. Medical and Occupational Health Department, Tata Motors Ltd. (India's largest commercial vehicle manufacturer and Global automotive giant) Pantnagar, India

\subsection{6/oemed-2018-ICOHabstracts.63}

Introduction Tata Motors Limited, a USD 42 billion organisation, is a leading global automobile manufacturer with a portfolio that covers a wide range of cars, sports vehicles, buses, trucks and defense vehicles. Our marque can be found on and off-road in over 175 countries around the globe. Sustainability and the spirit of 'giving back to society' is a core philosophy and good corporate citizenship is strongly embedded in our DNA. Our design and R and D centres located in India, the UK, Italy and Korea strive to innovate new products that achieve performances that will fire the imagination of GenNext customers. It employs more than 60000 permanent employees and most of the employees work in various shop floors like assembly unit, power train, welding and painting unit and in ERC (Engineering Research Centre). Such type of working places pre-disposes employees to various type of workplace accidents, which include but are not limited to slip, trip, falls, lacerations, fractures, polytrauma, weld injury, blunt trauma, foreign body in eye and so forth. Most of these accidents are due to behavior-based safety (BBS). So, to reduce these occurrences, it was decided to target unsafe behaviours of employees working in such places with the help of World leaders in safety - DuPont that works on the principle 'All accidents are preventable'. One of the most effective tool for addressing behavior-based safety is 'Safety observations' in these areas.

Methods Safety observation is a kind of safety round undertaken in various areas which addresses unsafe act (80\% prevalence) and unsafe conditions (20\% prevalence). It is done by taking a round of workplace observing people working in an unsafe manner and then, actually making contact with them. It uses 6 step process (observe, comment on what the employee was doing safely, discuss consequences of unsafe acts and safer ways of doing job, take agreement for working safely in future, discuss any other safety issues and thanking the employee). All employees perform safety observation each week and it has proved a great tool for eliminating unsafe acts/conditions and thereby reducing/preventing accidents at workplace and simultaneously improving behaviour towards safety and morale of employees. 